\title{
Convective heat transfer investigations at parts of a generator circuit breaker
}

\author{
T. Magier ${ }^{1}$, H. Löbl ${ }^{1}$, S. Großmann ${ }^{1}$, M. Lakner ${ }^{2}$ \\ \& T. Schoenemann ${ }^{2}$ \\ ${ }^{1}$ Dresden University of Technology, \\ Laboratory of Electrical Power Systems and High Voltage Engineering, \\ Dresden, Germany \\ ${ }^{2}$ ABB Switzerland AG, High Voltage Technology High Current Systems, \\ Zürich, Switzerland
}

\begin{abstract}
Current carrying equipment for power engineering is getting smaller and more compact in order to meet customer demands. In spite of small dimensions it should be able to carry still growing currents, which lead to high current densities in the current carrying parts and therefore in high heating of these parts. Due to small dimensions the heat transfer from these parts is restricted too. To assure that the maximum temperature rise in equipment parts stays under the allowed temperature rise fixed in the standards, the temperatures in these parts should be calculated first (for instance with thermal networks).

The power losses produced in the current carrying parts are transferred through convection, radiation and conduction from these parts to the ambient. For better cooling effectiveness several heat sink types, for example on the parts of generator circuit breakers can be used. To improve the accuracy of convective heat transfer calculation with thermal networks, the $\mathrm{n}_{1}, \mathrm{c}_{1}$ factors for affinity function $\mathrm{Nu}=\mathrm{c}_{1}(\mathrm{GrPr})^{\mathrm{n} 1}$ for natural convection, depending on the angle of the heat sink to the airflow, have been determined experimentally. Another point of thermal investigation is heat sink cooling with air, while the air is pre-warmed by other hot parts below the heat sink. This kind of interaction appears particularly in very compact devices and should therefore be investigated for a better accuracy of temperature calculation with thermal networks. Investigations have been carried out for different average temperatures of the heat plate, which was placed below the heat sink and for different heat sink positions.

Keywords: thermal networks, heat transfer coefficient, affinity function, natural convection.
\end{abstract}




\section{Introduction}

As a result of still increasing operating currents and decreasing dimensions of the current currying equipment, which results in high temperatures of the current path and the enclosure, a correct thermal design for this equipment is more important than ever. All temperatures along the current path should stay under temperature limits given in adequate standards (for generator circuit breaker [1]). For a generator circuit breaker operating at maximum ambient temperature $\vartheta_{0}=40^{\circ} \mathrm{C}$ the maximum allowable temperature is $\vartheta_{\max }=105^{\circ} \mathrm{C}$ at silver-coated contacts and $\vartheta_{\max }=70^{\circ} \mathrm{C}$ (in some cases $80^{\circ} \mathrm{C}$ ) on the enclosure. Because of small dimensions and compact design of such devices the current densities in the current path are comparatively high and heat transfer from these device's parts to the ambient is restricted. In order to increase the heat transfer from these parts to the cooling medium, additional heat sinks have to be used. They can be located on the current path (fig. 1a) or on the enclosure (fig. 1b).
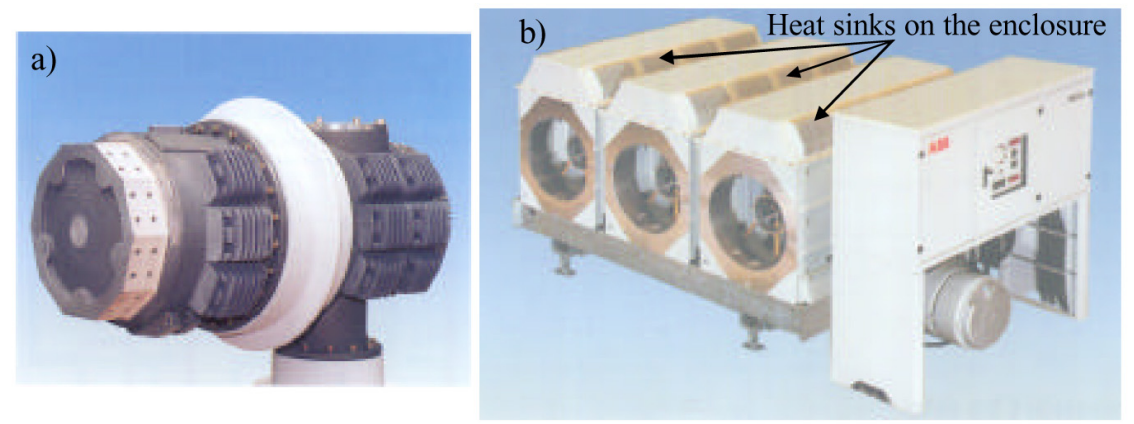

Figure 1: Heat sinks located on: a) current path and on b) enclosure

To improve the current carrying capacity of generator circuit breaker or other current carrying devices and for accelerating the development process of new devices thermal network models are used to predict the behaviour of the device. These models allow temperature calculation of device's parts and examination of several changes in device's design as well. In order to use thermal network models for development and improvement of electrical devices fundamental research on convective heat transfer were carried out. The following article deals with experimental convective heat transfer investigations at parts of generator circuit breaker. A method will be shown how to determine the $\mathrm{n}_{1}, \mathrm{c}_{1}$ parameters for affinity function $\mathrm{Nu}=\mathrm{c}_{1}(\mathrm{GrPr})^{\mathrm{n} 1}$ (free convection) for two heat sink types, depending on heat sink's position in the air flow.

\section{Temperature calculation with thermal networks - fundamentals}

The thermal network method, based on the analogy between electrical and thermal field, allows one to calculate the temperature distribution in electrical 
devices. The thermal heat transfer between a device's parts and from these parts to the ambient can be calculated as well $[2,5]$. For the temperature calculation the device's model has to be "imaginary" divided into n- "slices". Each slice (fig. 2) is represented by thermal sources (thermal power losses in current path and in an enclosure $P_{L}$ and $\left.P_{K}\right)$, convective $\left(R_{K 1}, R_{K 2}, R_{K 3}\right)$, radiative $\left(R_{S 1}, R_{S 2}\right)$ and conductive $\left(R_{L}\right)$ resistances and for forced convection by the thermal resistance of the coolant stream $R_{\dot{V}}$. For dynamic temperature calculation the heat capacities $\mathrm{C}_{\mathrm{L}}$ and $\mathrm{C}_{\mathrm{K}}$ have to be included.

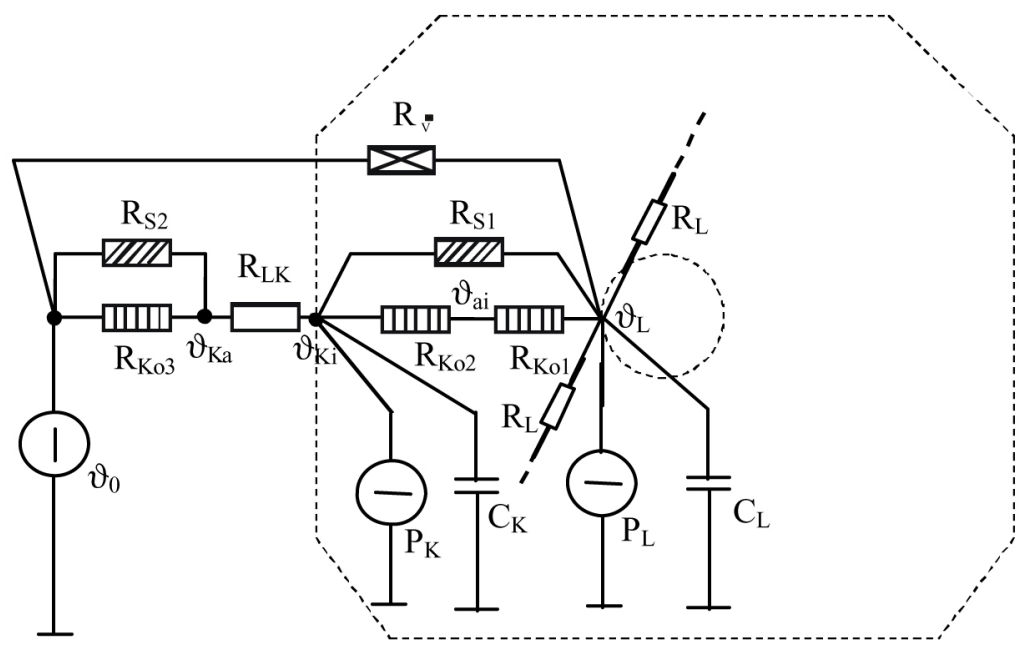

Figure 2: Thermal network for one section (slice) of generator circuit breaker.

Thermal power losses produced in the current path with temperature $\vartheta_{\mathrm{L}}$ are convoyed partially via convection $\left(\mathrm{R}_{\mathrm{Ko1}}\right)$ to the interior air with a temperature $\vartheta_{\mathrm{ai}}$ and from there to the internal side of the enclosure $\left(\mathrm{R}_{\mathrm{Ko} 2}\right)$ with $\vartheta_{\mathrm{Ki}}$. Another part of thermal power losses produced in current path is convoyed via radiation $\left(\mathrm{R}_{\mathrm{S} 1}\right)$ directly to the internal side of the enclosure and via conduction $\left(\mathrm{R}_{\mathrm{L}}\right)$ across the current path to the neighbouring sections (layers). The power losses arising from the current path to the internal side of enclosure sum up with power losses produced in this enclosure $\left(\mathrm{P}_{\mathrm{K}}\right)$ and are convoyed via conduction $\left(\mathrm{R}_{\mathrm{LK}}\right)$ to the outer side of the enclosure. From there, the power losses are transferred via convection $\left(R_{K_{03}}\right)$ and radiation $\left(R_{\mathrm{S} 2}\right)$ to the ambient air with the temperature $\vartheta_{0}$.

In case of cooling via forced convection, the volume stream of cooling air $\left(R_{\dot{V}}\right)$ convoys a major part of thermal power losses from current path directly to the ambient air. 
Each element of the thermal network can be described with adequate equations (Table 1).

The accuracy of temperature calculations with thermal networks depends significantly on the accuracy of input parameters in equation (1) to (9) used for calculation. Assuming that the geometrical dimensions $\left(l, d, l_{w}, A, O_{K o}, O_{S}\right)$ are known, other parameters and physical constants depending on material, temperature and so on can be in most cases found in the literature. In some cases, especially for seldom-used geometries, or for common geometries under special conditions some parameters must be determined experimentally. In the following, experiments for determination of $\mathrm{c}_{1}, \mathrm{n}_{1}$ parameters at free convection (eqn. (4)) and $c_{2}, n_{2}$ parameters at forced convection (eqn. (5)) on heat sinks under special conditions will be described.

Table 1: $\quad$ Equations describing thermal network elements.

\begin{tabular}{|c|c|c|}
\hline Thermal network elements & Equations & \\
\hline $\begin{array}{l}\text { Power losses in current path } \mathbf{P}_{\mathbf{L}} \text { and in } \\
\text { enclosure } \mathbf{P}_{\mathbf{K}}\end{array}$ & $P_{L}=k I^{2} \frac{\rho_{20} l}{A}\left[1+\alpha_{T}\left(\vartheta-20^{\circ} C\right)\right]$ & (1) \\
\hline $\begin{array}{l}\text { Thermal conduction resistance } \\
\mathbf{R}_{\mathbf{L}} \text { between parallel surfaces }\end{array}$ & $R_{L}=\frac{d}{\lambda A}$ & (2) \\
\hline Convective resistance $\mathbf{R}_{\mathbf{K o}}$ & $R_{K o}=\frac{1}{\alpha_{K o} O_{K o}}$ & (3) \\
\hline $\begin{array}{l}\text { Convective heat transfer coefficient } \boldsymbol{\alpha}_{\mathbf{K o}} \\
\text { for free convection: }\end{array}$ & $\alpha_{K o}=\frac{\lambda}{l_{W}} N u=\frac{\lambda}{l_{W}} c_{1}(G r \operatorname{Pr})^{n_{1}}$ & (4) \\
\hline $\begin{array}{l}\text { Convective heat transfer coefficient } \boldsymbol{\alpha}_{\mathbf{K o}} \\
\text { for forced convection: }\end{array}$ & $\alpha_{K o}=\frac{\lambda}{l_{W}} N u=\frac{\lambda}{l_{W}} c_{2} \operatorname{Re}^{n_{2}}$ & (5) \\
\hline Radiation resistance $\mathbf{R}_{\mathbf{S}}$ & $R_{S}=\frac{1}{\alpha_{S} O_{S}}$ & (6) \\
\hline Heat transfer coefficient of radiation $\alpha_{\mathbf{S}}$ & $\alpha_{S}=\varepsilon_{12} C_{S} \frac{T_{2}^{4}-T_{1}^{4}}{\vartheta_{2}-\vartheta_{1}}$ & (7) \\
\hline $\begin{array}{l}\text { Thermal resistance of the coolant } \\
\text { stream by forced convection } \mathbf{R}_{\dot{\mathbf{v}}}\end{array}$ & $R_{\dot{V}}=\frac{1}{2 c_{P} \rho \dot{V}}$ & (8) \\
\hline Thermal Capacity $\mathbf{C}_{\mathbf{W}}$ & $C_{W}=c_{W} m$ & (9) \\
\hline
\end{tabular}

\section{Determination of $c_{1}, n_{1}$ parameters depending on heat sink's angle to horizontal position $\left(c_{1}=f\left(\alpha_{H}\right), n_{1}=f\left(\alpha_{H}\right)\right)$}

A heat sink on the current path or on the enclosure of a generator circuit breaker can be placed with different angles to the ascending, cooling air (fig. 1). This can result in different values of the convective heat transfer coefficient $\alpha_{\mathrm{Ko}}$ and $\mathrm{c}_{1}, \mathrm{n}_{1}$ parameters for each heat sink position. To improve the accuracy of temperature calculation with thermal networks, experimental thermal investigations to determine these parameters on two different heat sinks were carried out. The 
smaller heat sink (fig. 3a), hereinafter called "HS1", has a characteristic length $1_{\mathrm{W}}=107 \mathrm{~mm}$, a convective surface $\mathrm{O}_{\mathrm{Ko}}=0,098 \mathrm{~m}^{2}$ and a radiating surface $\mathrm{O}_{\mathrm{S}}=0,034 \mathrm{~m}^{2}$. The bigger one ("HS2" fig. 3b) has a characteristic length $1_{\mathrm{W}}=330 \mathrm{~mm}$ and respectively $\mathrm{O}_{\mathrm{Ko}}=0,399 \mathrm{~m}^{2}$ and $\mathrm{O}_{\mathrm{S}}=0,09 \mathrm{~m}^{2}$. Both heat sinks were mounted on separate heat plates with controllable electric power. The power was measured with a power meter LMG 95. The heat plates were thermally insulated from the ambient with mineral wool, so that the major part of the supplied power was delivered to the ambient via the heat sink. The heat sink-, heat plate-, insulation- and ambient-temperatures were measured with thermocouples and all data were transferred to the PC data acquisition - system. The heat sinks angle to the horizontal position $\alpha_{\mathrm{H}}$ was changed from $0^{\circ}$ to $120^{\circ}$ for $\mathrm{HS} 1$ and from $0^{\circ}$ to $90^{\circ}$ for HS2 (fig. 3c).
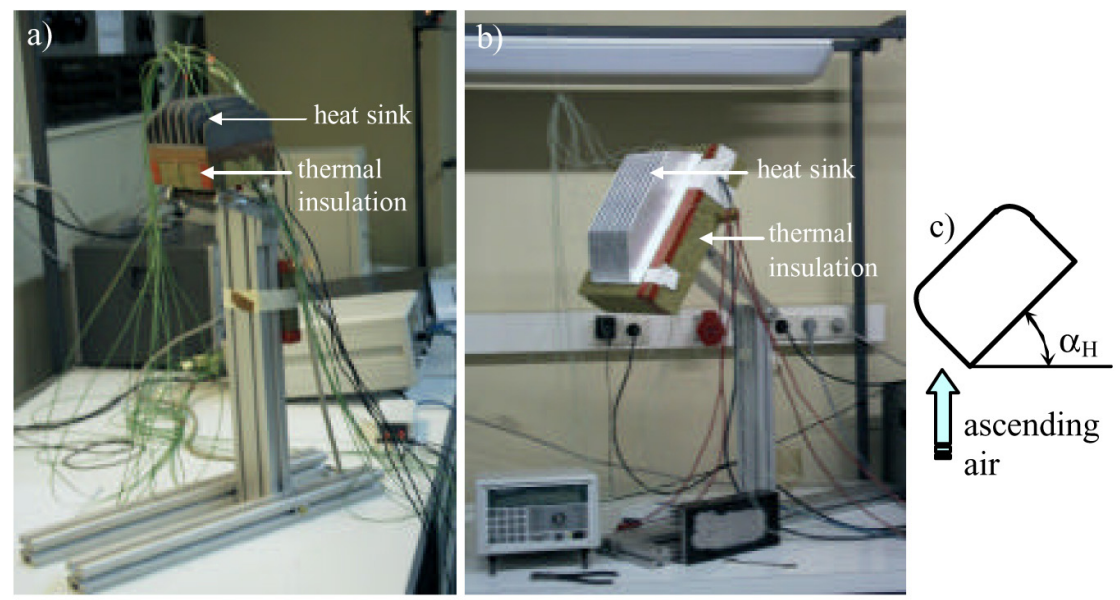

Figure 3: Test arrangement for thermal investigations on heat sinks HS1 (a) and HS2 (b) by different angle $\alpha \mathrm{H}$ to horizontal position (c)

The convective dissipation of heat $P_{K o}$ (fig. 4) can be calculated from:

$$
P_{K o}=P_{e l}-\left(P_{I s}-P_{S}\right)
$$

where $P_{e l}$ is the supplied electrical power, $P_{I s}$ is the dissipated heat through the thermal insulation and $P_{S}$ is the dissipated heat via radiation given by:

$$
P_{S}=\varepsilon_{12} C_{S} O_{S} 10^{-8}\left(T_{1}^{4}-T_{2}^{4}\right) \text {. }
$$

Resultant emissivity $\varepsilon_{12}$ in equation (11) was determined by dint of a pyrometer to $\varepsilon_{12}=0,96$ for HS1 and $\varepsilon_{12}=0,3$ for HS2. $C_{S}$ is the radiation capability of the "black body" $\left(\mathrm{C}_{\mathrm{s}}=5,67 \mathrm{Wm}^{-2} \mathrm{~K}^{-4}\right)$ and $T_{1}$ and $T_{2}$ are absolute temperatures of the heat sink and the ambient respectively.

The heat leak through the thermal insulation $P_{I_{s}}$ was determined by calibration. For calibration each heat sink was replaced by an insulating plate and the temperature difference $\Delta \vartheta$ between the heat plate and the insulation was 
measured at different supplied power values. This heat dissipated through the thermal insulation, for an ascertained temperature difference $\Delta \vartheta$, was then subtracted from the supplied power in experiments conducted with heat sinks (fig. 4).

After the calculation of $P_{S}$ and the determination of $P_{I_{S}}$ the convective heat flow $P_{K o}$ could be calculated.

For known $P_{K o}$, the Nußelt - number $N u$ in eqn. (4) given by:

$$
N u=c_{1}(G r \operatorname{Pr})^{n_{1}}
$$

can also be calculated from:

$$
N u=\frac{P_{K o} l_{w}}{O_{K o} \Delta \vartheta \lambda}
$$

For determination of $c_{1}$ and $n_{1}$ parameters in eqn.(4 and 6) the Grashof - number Gr must be known too. It is given by:

$$
\operatorname{GrPr}=k_{s} \Delta \vartheta l_{w}^{3}
$$

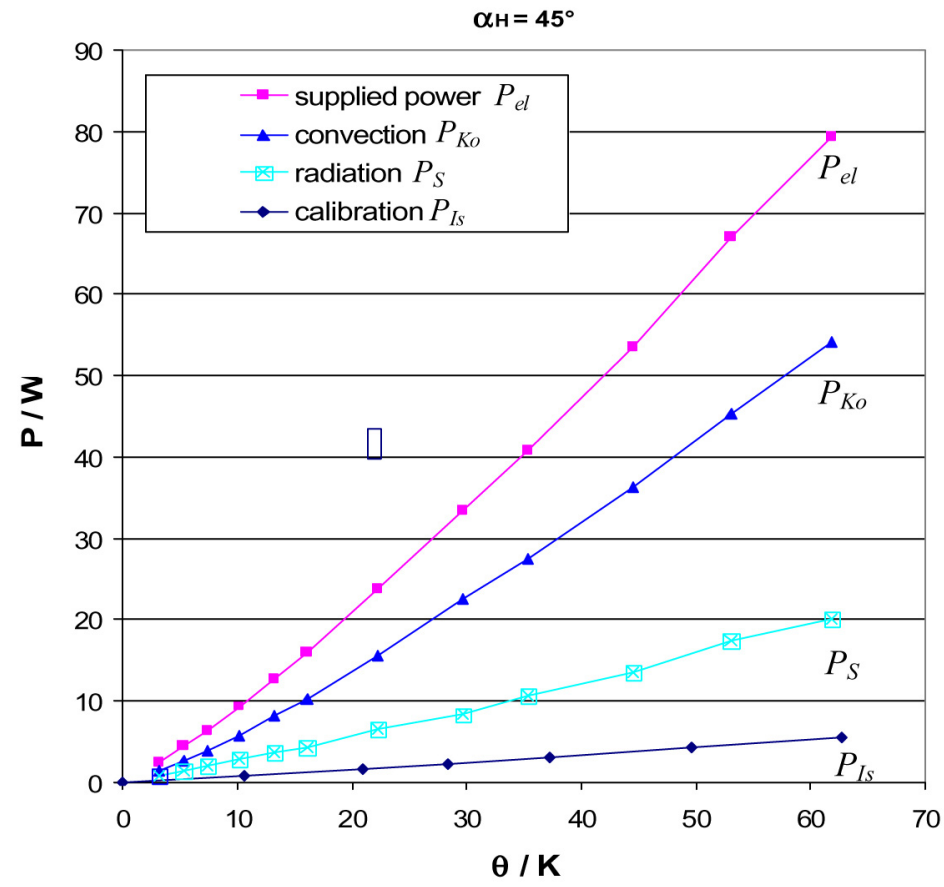

Figure 4: $\quad$ Supplied electrical power $P_{e l}$, convective dissipated heat $P_{K o}$, via radiation dissipated heat $P_{S}$, and through the thermal insulation dissipated heat $P_{I s}$ versus temperature difference between heat plate and outer side of the thermal insulation (HS1, angle to the horizontal position $\alpha \mathrm{H}=45^{\circ}$ ). 
Because of the two unknown parameters $c_{1}$ and $n_{1}$ in eqn. (12) this eqn. can't be calculated. By logarithm each side of eqn. (12) it can be rewritten as:

$$
\log \mathrm{Nu}=\log \mathrm{c}_{1}+\mathrm{n}_{1} \log (\mathrm{GrPr})
$$

and then be solved graphically via double-logarithmic diagram [3, 4].

The substitution of $\log \mathrm{Nu}$ by $\mathrm{A}, \log (\mathrm{GrPr})$ by $\mathrm{B}$ and $\log \mathrm{c}_{1}$ by $\mathrm{C}$ results in a linear equation:

$$
A=n_{1} B+C
$$

in which $\mathrm{n}_{1}$ and $\mathrm{C}$ can be determined graphically. Putting the investigation results for free convection in a diagram where $\log \mathrm{Nu}$ is the ordinate and $\log (\mathrm{GrPr})$ the abscissa, the results build a straight line so that the $\mathrm{n}_{1}, \mathrm{c}_{1}$ parameters can be determined.

In this way the determined parameter $n_{1}$ was approximately $n_{1}=0,33$ in the whole range of $\alpha_{H}$ angle. In affinity theory this value of $\alpha_{H}$ indicates a turbulent airflow and therefore it has been set up for further calculations for each $\alpha_{H}$ angle. With this value of $n_{1}$ parameter the $c_{1}$ parameter for both HS1 and HS2 was calculated (fig. 5) from:

$$
c_{1}=\frac{N u}{(G r P r)^{n}}
$$

In fig. 5 is clearly to see, that $\mathrm{c}_{1}$ parameter and therefore convective heat transfer from the heat sink to the ambient depends for HS1 and HS2 on $\alpha_{\mathrm{H}}$ angle. Both heat sinks have the best cooling performances for $\alpha_{H}$ in range between $\alpha_{H}=60^{\circ}$ and $\alpha_{\mathrm{H}}=90^{\circ}$.

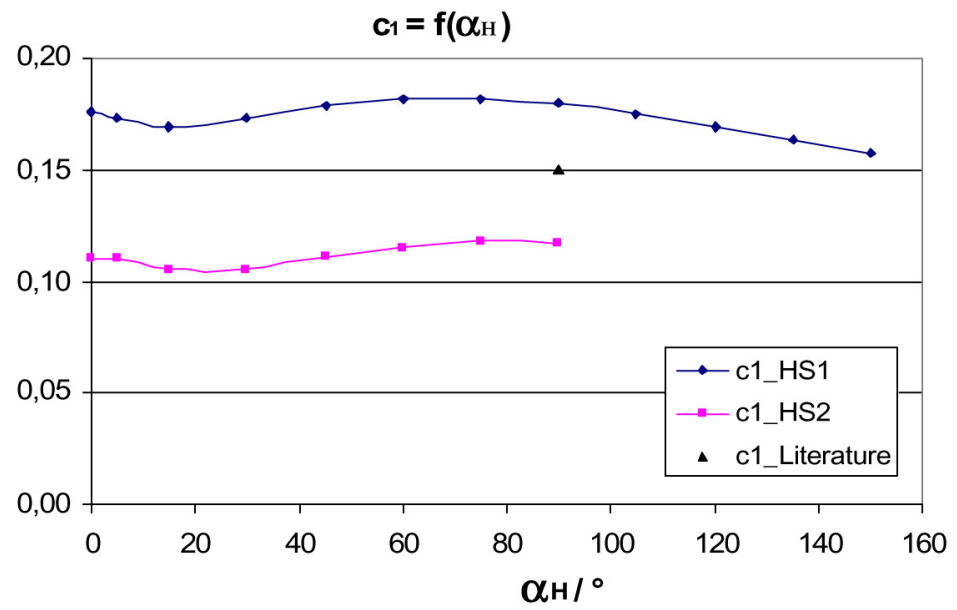

Figure 5: Parameters $\mathrm{c} 1$ by $\mathrm{n} 1=0,33$ for different heat sink angle $\alpha \mathrm{H}$ to the horizontally position. 
Furthermore it can be seen, that $\mathrm{c}_{1}$ parameter for HS1 achieves much higher values then $c_{1}$ parameter for HS2. The $c_{1}=0,15$ given in [3] for $\alpha_{H}=90^{\circ}$ lies between the values of the $c_{1}$ parameters for HS1 and HS2. This difference is caused by different characteristic length $1_{w}$ for each heat sink. After air passes a certain critical length between fins, its temperature and therefore pressure drop increases. Thus decreases the heat sink cooling performance. It is therefore advantageous if the characteristic length $1_{w}$ of the heat sink isn't too long.

\section{Determination of $c_{1}, n_{1}$ parameters depending on heat sink's angle to horizontal position by heat sink cooling with pre-warmed air}

In some cases heat sinks in current carrying devices are placed above other hot parts and therefore they are cooled with air that is warmer then ambient air. In order to estimate that effect on the heat sink's cooling performance thermal investigations have been performed. The test arrangements described above were modified so that $1000 \mathrm{~mm}$ x $250 \mathrm{~mm}$ stainless steel heat plates below each heat sink were integrated (fig. 6). Measurements analogous to point 3 for two different heat plate power levels (HP1: $40 \mathrm{~W}$; HP2: $80 \mathrm{~W}$ ) were carried out. In order to achieve uniform current distribution in the heat plates and therefore uniform temperature distribution in the heat plate DC current was used. The heat plate temperature rise was approximately $26 \mathrm{~K}$ for HP1 and $46 \mathrm{~K}$ for HP2 power level. Reference temperature was the ambient temperature $\vartheta_{0}$.

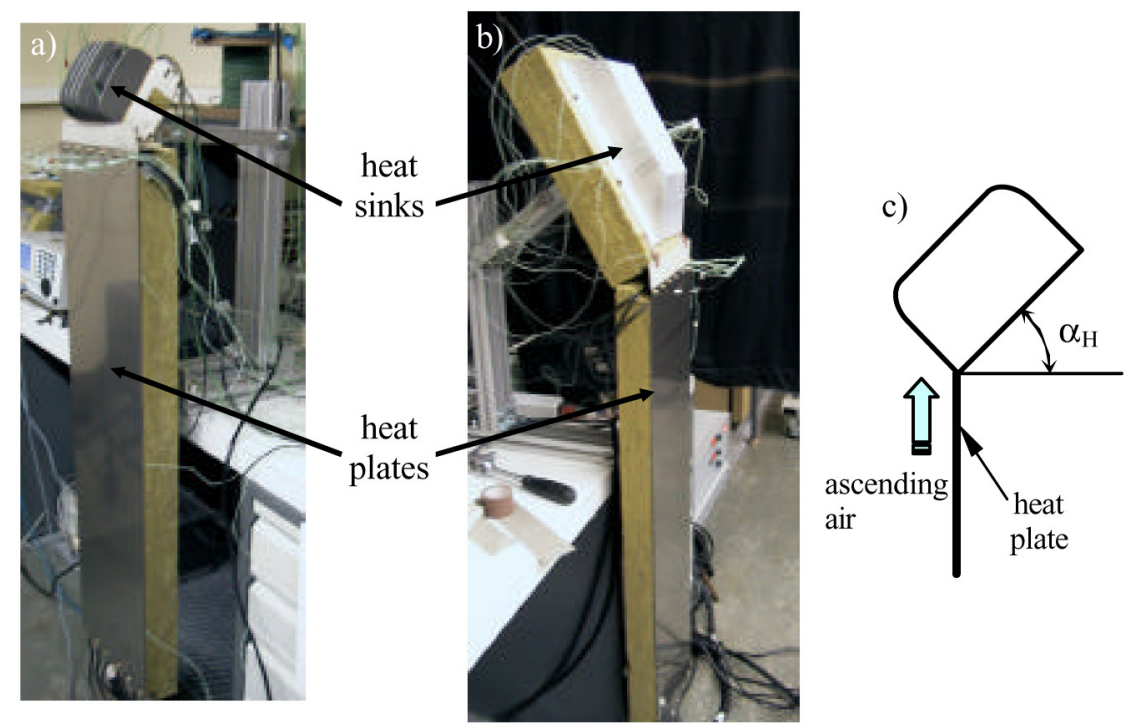

Figure 6: Test arrangement for thermal investigations on heat sink HS1 (a) and HS2 (b) for different angle $\alpha_{H}$ to horizontal position by cooling with pre-warmed air. 
For small $\alpha_{H}$ angles $\left(0^{\circ}\right.$ to $\left.30^{\circ}\right)$ heat plates below heat sinks have only a little influence on $\mathrm{c}_{1}$ factors for both HS1 and HS2 (fig. 7). In that case the major part of ascending warm air flows over the heat sink fins. For $\alpha_{\mathrm{H}}$ equal or bigger than $60^{\circ}$ the heat plates directly below the heat sink can even slightly increase the heat sink's cooling performance. The ascending air, which was pre-warmed by a hot plate, is warmer than the surrounding air and therefore can pass between cooling fins faster than cold air. That can also cause air turbulences by passing cooling fins, which improve heat transfer between heat sink and the ambient air. The increased temperature of the cooling air is compensated by a higher air velocity.

The heat plate temperatures examined in experiment were smaller than the heat sinks temperature for each power level. If the heat plate placed below the heat sink is too warm (approximately as warm as heat sink temperature or warmer) the cooling air can be too hot for efficiently cooling the heat sink even with higher air velocity. In such a case the cooling performance of the heat sink placed above heat plate can decrease.

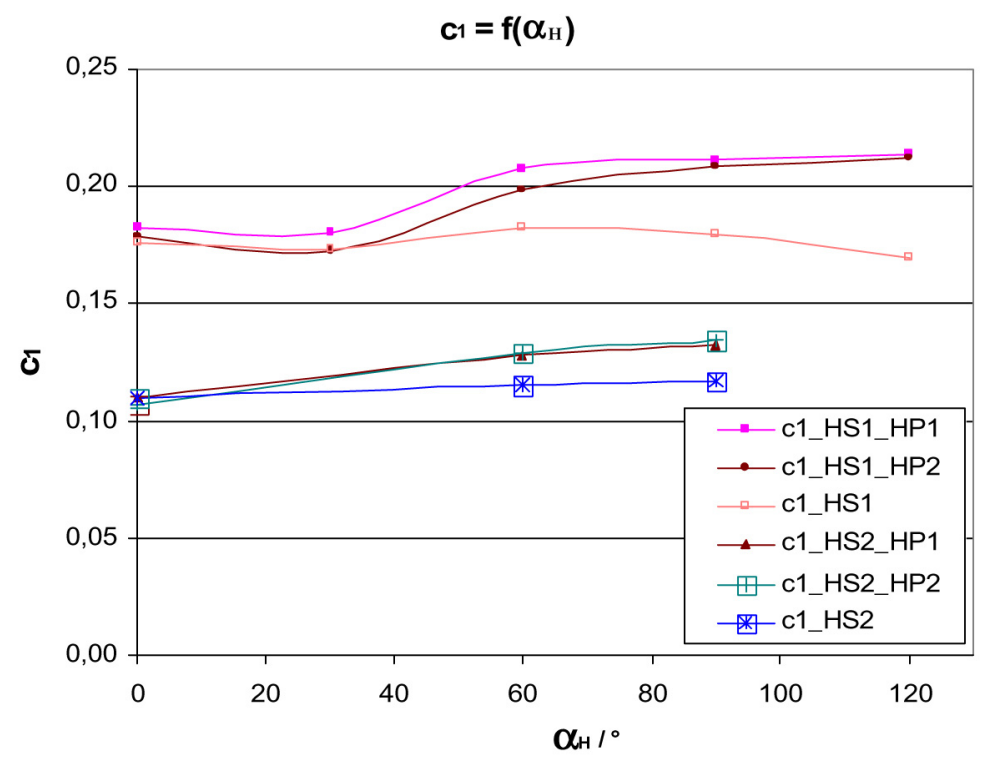

Figure 7: Parameter $\mathrm{c} 1$ for different heat sink angles $\alpha \mathrm{H}$ to the horizontal position and different power levels of the heat plates below heat sinks.

\section{Summary}

In order to calculate the temperatures of current carrying devices with thermal networks accurately, thermal investigations by free convection on heat sinks, 
used in such devices, were carried out. These investigations showed that in addition to the geometry and the dimensions of the heat sink its position to the airflow must be considered too. Further, the influence of the presence of other hot parts below the heat sink was investigated. The results for this experiment shown in fig. 7 indicate only a slight influence of such parts on the cooling performance of the heat sink. In case of heat plates placed below heat sinks, whose temperatures are lower than the heat sink temperature and with heat sink angles to horizontal position $\alpha_{H}$ equal or bigger than $60^{\circ}$ the heat sinks cooling performance can even be slightly improved.

\section{References}

[1] IEEE C37.013-1997: IEEE Standard for AC High-Voltage Generator Circuit Breakers Rated on a Symmetrical Current Basis

[2] Löbl, H.: Zur Dauerstrombelastbarkeit und Lebensdauer der Geräte der Elektroenergieübertragung, Dissertation B, TU Dresden, 1985

[3] Löbl,H., Stoye, H.J.: Beiterag zur Optimierung elektrotechnischer Schaltund Verteileranlagen hinsichtlich ihrer thermischen Dauerstrombeanspurchung, Disseration A, TU Dresden, 1972

[4] Michejew,M.A.: Grundlagen der Wärmeübertragung, VEB Verlag Technik Berlin, 1964

[5] Schoeneman,T., Schenk, M., Löbl, H., Pleines, M., Magier, T., Optimal design of generator circuit breakers up to a capacity of 2000 MVA using thermal networks under consideration of electrical and thermal contact resistances, 50 th IEEE Holm Conference on Electrical Contacts, Seattle, 2004 